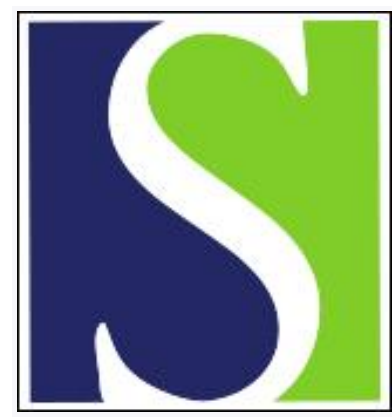

Scand J Work Environ Health 2013;39(5):486-494

https://doi.org/10.5271/sjweh.3365

Published online: 17 Apr 2013, Issue date: 01 Sep 2013

Risk and rate advancement periods of total hip replacement due to primary osteoarthritis in relation to cumulative physical workload

by Rubak TS, Svendsen SW, Søballe K, Frost P

This is the first longitudinal study examining the risk and timing of total hip replacement (THR) due to primary osteoarthritis in relation to independently assessed lifelong cumulative physical workload at a population level. Among men, the most highly exposed group had an odds ratio of 1.3, and in this group, THR was performed 3.4 years earlier in life.

Affiliation: Department of Occupational and Environmental Medicine, Copenhagen University Hospital, Bispebjerg, Bispebjerg Bakke 23, 2400 Copenhagen NV. lysetimer@gmail.com

Refers to the following texts of the Journal: 1992;18(1):59-63

1991;17(2):104-109 2011;37(1):30-36 2009;35(2):81-83

Key terms: cohort study; cumulative physical workload; epidemiology; excess fraction; exposure assessment; industry exposure matrix; osteoarthritis; physical workload; primary osteoarthritis; register study; risk and rate advancement period; risk estimation; total hip replacement

This article in PubMed: www.ncbi.nlm.nih.gov/pubmed/23595111

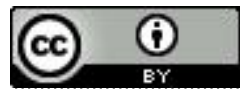




\title{
Risk and rate advancement periods of total hip replacement due to primary osteoarthritis in relation to cumulative physical workload
}

\author{
by Tine Steen Rubak, PhD, ${ }^{1,2}$ Susanne Wulff Svendsen, PhD, ${ }^{3}$ Kjeld Søballe, DMedSc, ${ }^{4}$ Poul Frost, PhD ${ }^{2}$
}

\begin{abstract}
Rubak TS, Svendsen SW, Søballe K, Frost P. Risk and rate advancement periods of total hip replacement due to primary osteoarthritis in relation to cumulative physical workload. Scand J Work Environ Health. 2013;39(5):486494. doi:10.5271/sjweh.3365
\end{abstract}

\begin{abstract}
Objectives This study aims to (i) evaluate relative risks, excess fraction of cases, and rate advancement periods for total hip replacement (THR) due to primary osteoarthritis in relation to lifelong cumulative physical workload and (ii) describe temporal trends in the proportion employed in the most highly exposed industries from 1986-2006.

Methods In a cohort study of the Danish working population, we assessed cumulative physical workload by combining year-by-year register information on employment industry with an industry exposure matrix that provided point scores ( $0-2)$ of physical workload. Cumulative physical workload was expressed as point-years corresponding to the pack-year concept of smoking. We retrieved register information on first-time THR during 1996-2006 and used a logistic regression technique to fit discrete time hazards models adjusting for age and other factors. We calculated excess fraction of cases and rate advancement periods.
\end{abstract}

Results Total numbers of point-years ranged from 0-86. For men, an exposure-response relation was observed reaching an odds ratio of 1.33 [95\% confidence interval $(95 \% \mathrm{CI}) 1.17-1.53]$ for the highest exposure category (35-86 point-years) compared to 0 point-years. The excess fraction of cases was $18 \%$, and THR took place up to 3.4 years earlier with increasing exposure. For women, no exposure-response relation was found.

Conclusions At the population level, cumulative physical workload increased the risk of THR among men, with surgery being performed slightly earlier in life. The proportion employed in the most highly exposed industries remained constant.

Key terms cohort study; epidemiology; excess fraction; exposure assessment; industry exposure matrix; register study; risk estimation.

Primary osteoarthritis $(\mathrm{OA})$ is the most common joint disorder in the world and often affects the knee and hip joints (1). In the US, the combined number of knee and hip joint replacements exceeds 350000 annually (1). In Denmark, $78 \%$ of all total hip replacements (THR) performed in 2010 were due to primary hip OA, $58 \%$ were performed among women, and $51 \%$ took place before the age of 70, ie, in the working age population (2).

For patients with primary hip OA, pain and disability are the most important indications for THR (3), which may be seen as an indicator of end-stage disease (4). End-stage OA is of public health concern in Western societies, among other things because of the influence on physical capacity also among working age people. Risk factors for primary hip OA include aging, hip injuries, constitutional predispositions (5), and a high body mass index (5-7).

It is a longstanding theory that mechanical wear and tear throughout life may be a contributing cause of primary hip OA (8). Several reviews have concluded that there is evidence of a causal relationship with physical workload (9-13). The reviews have also agreed that there is sparse knowledge of relations with cumulative exposures. Focusing on studies that included THR in their case definitions and applied some sort of cumulative exposure estimates, the body of literature is manageable. One cross-

1 Department of Occupational and Environmental Medicine, Copenhagen University Hospital, Bispebjerg, Denmark.

2 Danish Ramazzini Centre, Department of Occupational Medicine, Aarhus University Hospital, Aarhus, Denmark.

3 Danish Ramazzini Centre, University Department of Occupational Medicine, Herning Regional Hospital, Herning, Denmark.

4 Department of Orthopaedic Surgery, Aarhus University Hospital, Aarhus, Denmark. 
sectional study (14) and two case-control studies $(15,16)$ examined the risk of radio-graphically diagnosed OA or a previous THR among men in relation to duration of employment in jobs with a high physical workload. The studies reported an increased risk especially for those with $\geq 10$ years of employment as farmers or agricultural laborers $(14,15)$ or $>15$ years of employment in jobs with heavy lifting (16) when compared to men who had undergone intravenous urography (15) or pyelography (16) or men with sedentary work (14). The risk of THR or being on a waiting list for THR has been examined in four casecontrol (17-20) and one cohort study (21). Duration of employment in farm work was related to an increased risk in one of the case-control studies, which only included men (18). The remaining three studies relied on selfreported retrospective exposure information $(17,19,20)$. One of these studies included only men (19), one both men and women (17), and one only women (20). Significant associations with climbing stairs were observed for both men and women, while associations with cumulative lifting were observed for men only and with jumps for women only. For both men and women, the follow-up study reported an increased risk of THR with increasing number of years of employment as construction workers, farmers, and healthcare assistants as compared to office workers (21). Other case-control $(6,22,23)$ and cohort studies $(24,25)$ included THR in their case definitions, but did not use cumulative exposure estimates.

None of the aforementioned studies focused on the question whether THR is performed earlier in life with increasing cumulative physical workload $(26,27)$. Accelerated occurrence is not reflected in estimates of relative risk or excess fraction of cases (28). If a high cumulative physical workload is associated with advanced timing of THR, this will be of great public health concern. We are not aware of longitudinal studies examining the impact of lifelong cumulative exposures to physical workloads on risk and timing of THR at a population level.

The aim of this study was to evaluate the risk of THR due to primary OA in Denmark in relation to lifelong cumulative physical workload and assess the corresponding excess fraction of cases and rate advancement periods using information from nationwide registers. A further aim was to describe temporal trends in the proportion of the working population employed in the most highly exposed industries during 1986-2006.

\section{Methods}

\section{Design and population}

We conducted a register-based cohort study. Using data from the Danish Civil Registration System (CRS) (29) obtained in 2007, we identified all persons born in Denmark between 1 January 1925 and 31 December 1964. Persons were excluded if they had claimed protection against inquiries in connection with scientific studies. Through linkage with the Supplementary Pension Fund Register (30), we excluded those who had not reached ten years of full-time employment between 1964-2006; of note, periods of self-employment are not registered. We also excluded individuals living in Greenland, those who had emigrated or died before 1 January 1996 or before reaching ten years of full-time employment, and those who had a hospital diagnosis of primary hip OA between 1977-1995 (both years included) according to the National Patient Register (NPR) (31) as this could reflect prior joint surgery. Furthermore, we excluded those who had missing information on socioeconomic status (SES), see below.

\section{Outcome and follow-up}

Outcome was defined as first-time THR due to primary OA. Information on type and date of surgery was collected from the NPR. Until 1 January 1994, diagnosis was based on ICD-8 codes (osteoarthrosis coxae: 713.00) and thereafter on ICD-10 codes (arthrosis coxae primaria: M16.0, M16.1, M16.9). From 1 January 1996, and onwards, operations were registered in accordance with the NOMESCO Classification of Surgical Procedures (hip replacement surgery: KNFB20, KNFB30, KNFB40, KNFB99).

Follow-up time was calculated from 1 January 1996, or the beginning of the first year after obtaining $\geq 10$ years of fulltime employment, whichever came last, until the year of THR due to primary OA or censoring due to (i) THR for other reasons than primary OA, (ii) emigration, (iii) death, or (iv) end of follow-up by 31 December 2006, whichever came first.

\section{Exposure assessment}

For each individual and year of employment since 1964, we obtained information on industry and degree of employment (part-, full-, or over-time), from the Supplementary Pension Fund Register. The register applied 111 industries of employment according to the Danish Industrial Classification of All Economic Activities 2003 (32).

Information on industry of employment was linked to an industry exposure matrix (IEM) developed for the purpose of this study. Three of the authors independently rated the overall physical workload to the hip in each industry on a 3-point scale: $0=$ minimal load, $1=$ moderate load, and 2=high load. Exposures taken into consideration were primarily total load lifted per day but also - in order of priority - frequency of lifting 
burdens weighing $\geq 20 \mathrm{~kg}$, whole-body vibration, and standing/walking the majority of the working day. A similar approach for tripartition of professions according to overall manual exposures has been described previously (33). Two of the authors were senior consultants in occupational medicine and the third was a junior doctor in specialty training within occupational medicine. Ratings agreed for 103 of the 111 groups (93\%), and the difference between ratings never exceeded one point, meaning that at least two authors agreed for all groups. Final ratings were reached by majority decision with consent from the author whose rating stood alone. Examples of industries with minimal physical workload were "secondary education" and "financial institutions". Industries with moderate load included "restaurants" and "hospital activities". Highly exposed industries were, for instance, "bricklaying", "agriculture", and "production etc. of meat and meat products".

For each individual, we calculated point-years, a cumulative estimate of physical workload, as number of employment years (adjusted to full-time employment) in a specific industry times the corresponding score of physical workload from the IEM and summarized across all registered employments (34). This calculation corresponds to the pack-year concept used for tobacco consumption. It was possible for participants to accumulate exposure points during the follow-up period.

\section{Socioeconomic status}

Information on SES was gathered from Statistics Denmark. SES from 1980 was used for those born 1925 1935, while SES from 1986, 1996, and 2006 was used for those born 1936-1945, 1946-1955 and 1956-1964, respectively. If SES for the relevant year was missing, the nearest informative SES was used. Based on the coding schemes of Statistics Denmark, we created a common classification of SES with five groups: (i) selfemployed and their spouses, (ii) upper level top managers and employees, (iii) intermediate level employees, (iv) basic level employees or those with missing information on skill level, and (v) persons outside the labor market or unemployed.

\section{Ethics}

The Danish Data Protection Agency approved the study. In Denmark, register studies do not need to be approved by the Committee System on Biomedical Research Ethics.

\section{Statistical analysis}

We calculated correlation coefficients and $95 \%$ confidence intervals $(95 \% \mathrm{CI})$ between cumulative physi- cal workload and age at start of individual follow-up, and between cumulative physical workload at start of individual follow-up and SES at age $40-55$ years. The risk analysis of THR was stratified by sex. We used a multiple logistic regression technique including number of follow-up intervals (years) to fit discrete time hazard models including cumulative physical workload and age as time varying variables (35). Main analyses were performed with an exposure time lag of one year. We categorized the total number of point-years into six groups. The following upper cut-off levels were chosen: 0 (reference group), 5, 15, 25, 35, and 86 point-years. We selected cut-off levels based on the total distribution of point-years to obtain exposure groups of approximately equal size, while ensuring exposure contrast and comparability between men and women. Each person could contribute to more than one exposure category during follow-up. Furthermore, we analyzed point-years as a continuous exposure variable.

A priori, we decided to include age (time varying), SES (group 1 as reference), county of residence, and calendar year in the full model. Analyses were repeated using age 70 years as an additional censoring criterion. SES was included to serve as a proxy for individual confounders, eg, obesity and physical activity.

In case of increased risks [odds ratio (OR)], we estimated the potential for prevention by calculating the excess fraction of THR that could be attributed to cumulative physical workload by multiplying the aetiologic fraction, $\left(\mathrm{OR}_{\text {adjusted }}-1\right) / \mathrm{OR}_{\text {adjusted }}$ for each exposure category with the number of cases within the exposure category, then summing up the excess numbers (integer parts) of THR across all exposure categories, and finally dividing the sum by the total number of THR (36). The risk of THR increased monotonically with age and, to calculate rate advancement periods (years), we included age as a continuous variable in the regression model. We used adjusted coefficients and variance estimates from the logistic regression analysis to calculate rate advancement periods with $95 \% \mathrm{CI}(26)$.

Chronic pain and disability due to hip OA may lead to change of employment into less-exposed industries, which may lead to postponement or avoidance of THR. To evaluate potential health-related selection into less exposed industries, we analyzed whether a fall in IEM score - as compared to the persons' score three years previously - was associated with an increased risk of THR. Persons were only eligible for these analyses if they had been employed for at least one year since 1996 in industries with an IEM score $>0$ because otherwise they could not experience a fall in IEM score. We excluded persons who were not at risk of THR and those who were >65 years of age by 1 January 1999 .

We evaluated the effect of applying a lag time of three instead one year in analyses including all who 
were still at risk of THR and $<66$ years of age by 1 January 1999.

Main analyses were performed on Statistics Denmark's research platform using Stata 11.2 SE (StataCorp, College Station, TX, US).

\section{Results}

A total of 899549 women and 1010944 men were included in the study. Figure 1 shows how the study cohorts were established. Tables 1 and 2 depict the distribution of follow-up time, number of cases, age, and SES, according to categories of cumulative physical workload for women and men. At start of individual follow-up, the women and men were on average 48.2 and 49.1 years old, respectively, and the men had a higher mean cumulative physical workload (17.7 point-years) than the women (10.6 point-years). The correlation coefficient between cumulative physical workload and age was $0.173(95 \%$ CI $0.171-0.175)$ for women and 0.287 (95\% CI 0.275-0.289) for men, and the correlation coefficient between cumulative physical workload and SES was $-0.015(95 \%$ CI $-0.017--0.013)$ for women and 0.043 (95\% CI $0.041-0.045)$ for men.
The percentages of those aged 18-64 employed in IEM groups 0 and 1 changed over time, while the percentages working in IEM group 2 (the most highly exposed group) stayed constant both among women and men. In 1986,1996 , and 2006, respectively, $43 \%, 53 \%$, and $53 \%$ of the women were employed in industries belonging to IEM group 0 . For IEM group 1, the corresponding percentages were $47 \%, 38 \%$, and $36 \%$, while for IEM group 2 , the percentages were $10 \%, 9 \%$, and $11 \%$. Among men, the percentages employed in IEM group 0 increased from $30 \%$ to $37 \%$ and $41 \%$ in 1986,1996 , and 2006 , respectively. The corresponding percentages employed in IEM group 1 were $45 \%, 42 \%$, and $36 \%$, while the percentages employed in IEM group 2 were $25 \%, 21 \%$, and $23 \%$.

During 9126600 person years of follow-up, 8784 new cases of THR appeared among women. Among men, 9900 new cases were recorded during 10297402 person years of follow-up. Table 3 shows risk estimates for women. No increase in risk of THR was observed in relation to increasing cumulative physical workload. Age was the most important risk factor with an increased risk of $11 \%$ per year. Table 4 shows risk estimates for men. Both in the age- and the fully adjusted model, an exposure-response relation was seen for cumulative physical workload. Again, age was a strong risk factor with an increased risk of $9 \%$ per year. For both women

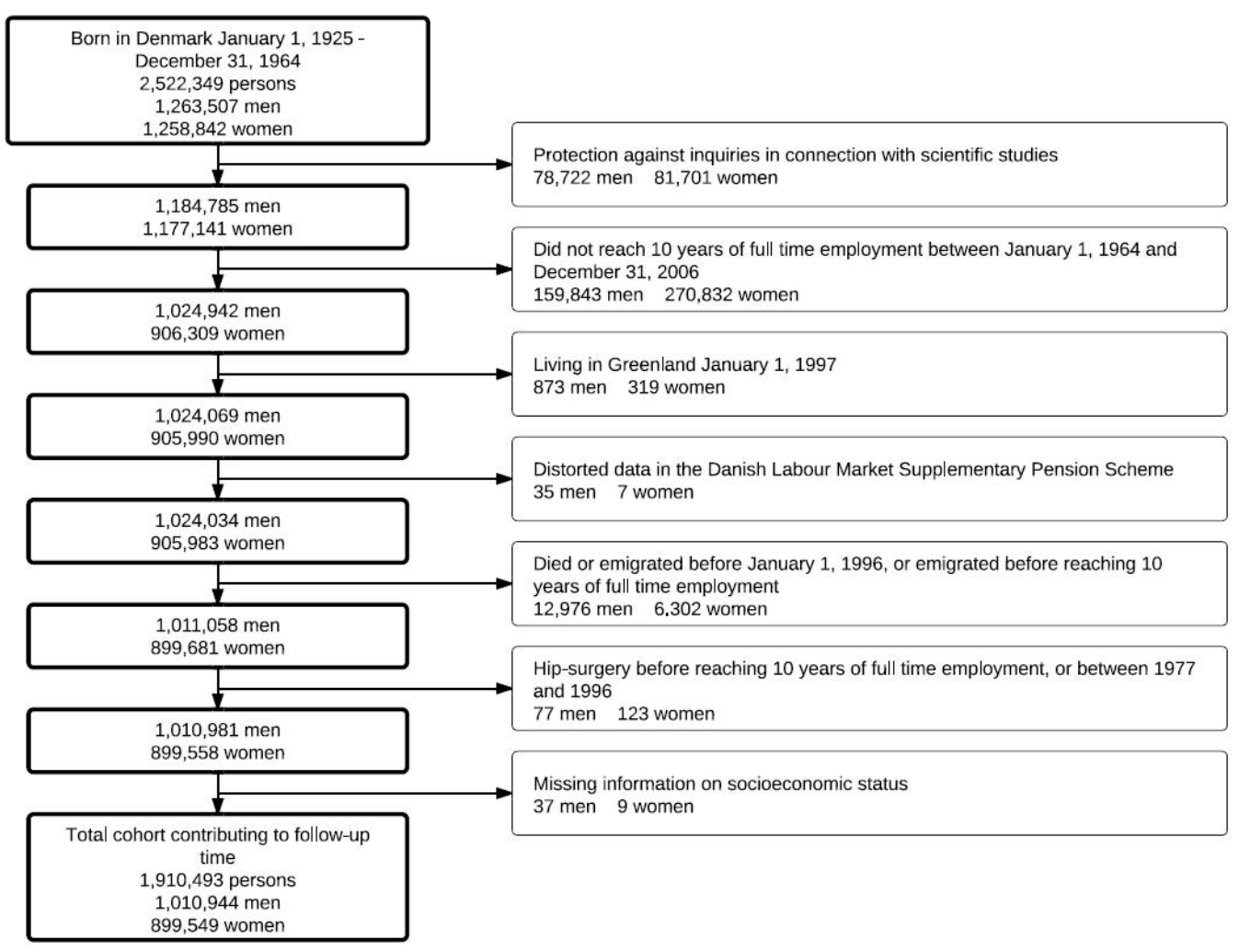

Figure 1. Flow chart from birth cohorts to study population. 
Table 1. Number of cases, follow-up time, and age at start of follow-up, according to categories of cumulative physical workload for women and men. [SD=standard deviation]

\begin{tabular}{|c|c|c|c|c|c|c|c|c|}
\hline \multirow{3}{*}{$\begin{array}{l}\text { Cumulative } \\
\text { physical workload } \\
\text { (point-years) }^{a}\end{array}$} & \multicolumn{4}{|c|}{ Women } & \multicolumn{4}{|c|}{ Men } \\
\hline & \multirow{2}{*}{$\begin{array}{c}\text { Cases } \\
\mathrm{N}\end{array}$} & \multirow{2}{*}{$\frac{\begin{array}{c}\text { Follow-up time } \\
\text { (years) }\end{array}}{\mathrm{N}}$} & \multicolumn{2}{|c|}{ Age } & \multirow{2}{*}{$\begin{array}{c}\text { Cases } \\
\mathrm{N}\end{array}$} & \multirow{2}{*}{$\begin{array}{c}\begin{array}{c}\text { Follow-up time } \\
\text { (years) }\end{array} \\
\mathrm{N}\end{array}$} & \multicolumn{2}{|c|}{ Age } \\
\hline & & & Mean & SD & & & Mean & SD \\
\hline 0 & 515 & 323223 & 51.5 & 11.4 & 242 & 186236 & 55.6 & 11.5 \\
\hline$>0-<5$ & 1720 & 2110311 & 46.4 & 9.4 & 755 & 1146384 & 46.0 & 9.1 \\
\hline $5-<15$ & 3159 & 3396281 & 47.3 & 10.0 & 2075 & 2617028 & 46.3 & 10.5 \\
\hline $15-<25$ & 2109 & 2162062 & 50.2 & 9.3 & 2447 & 2748192 & 48.6 & 10.5 \\
\hline $25-<35$ & 917 & 829540 & 52.8 & 8.4 & 2335 & 2090511 & 53.5 & 9.0 \\
\hline $35-86$ & 364 & 305183 & 53.6 & 7.9 & 2046 & 1509051 & 55.7 & 7.6 \\
\hline Total & 8784 & 9126600 & 48.2 & 9.9 & 9900 & 10297402 & 49.1 & 10.5 \\
\hline
\end{tabular}

a Point-years: years of full-time employment weighted by score of physical workload in employment industry.

Table 2. Distribution of socioeconomic status at age $40-55$ years, according to categories of cumulative physical workload for women and men.

\begin{tabular}{|c|c|c|c|c|c|c|c|c|c|c|c|c|c|c|}
\hline & \multicolumn{14}{|c|}{ Cumulative physical workload (point-years) ${ }^{a}$} \\
\hline & \multicolumn{2}{|c|}{0} & \multicolumn{2}{|c|}{$>0-<5$} & \multicolumn{2}{|c|}{$5-<15$} & \multicolumn{2}{|c|}{$15-<25$} & \multicolumn{2}{|c|}{$25-<35$} & \multicolumn{2}{|c|}{$35-86$} & \multicolumn{2}{|c|}{ Total } \\
\hline & $\mathrm{N}$ & $\%$ & $\mathrm{~N}$ & $\%$ & $\mathrm{~N}$ & $\%$ & $\mathrm{~N}$ & $\%$ & $\mathrm{~N}$ & $\%$ & $\mathrm{~N}$ & $\%$ & $\mathrm{~N}$ & $\%$ \\
\hline \multicolumn{15}{|l|}{ Women } \\
\hline Self-employed and their spouses & 956 & 2.7 & 10549 & 4.3 & 23773 & 6.3 & 5361 & 3.0 & 750 & 1.6 & 113 & 0.8 & 41502 & 4.6 \\
\hline $\begin{array}{l}\text { Top managers and employees at } \\
\text { upper level }\end{array}$ & 1571 & 4.3 & 7867 & 3.2 & 8445 & 2.2 & 4841 & 2.7 & 2056 & 4.4 & 486 & 3.5 & 25266 & 2.8 \\
\hline Employees at intermediate level & 18513 & 52.0 & 114437 & 46.4 & 149997 & 39.8 & 82616 & 46.0 & 24780 & 53.1 & 6691 & 48.3 & 397034 & 44.1 \\
\hline $\begin{array}{l}\text { Employees at basic level or with } \\
\text { missing information on skill level }\end{array}$ & 12778 & 35.9 & 86238 & 35.0 & 160224 & 42.5 & 80530 & 44.8 & 18330 & 39.3 & 6373 & 46.0 & 364482 & 40.5 \\
\hline $\begin{array}{l}\text { Persons outside the labor market } \\
\text { or unemployed }\end{array}$ & 1817 & 5.1 & 27446 & 11.1 & 34711 & 9.2 & 6355 & 3.5 & 758 & 1.6 & 187 & 1.4 & 71274 & 7.9 \\
\hline \multicolumn{15}{|l|}{ Men } \\
\hline Self-employed and their spouses & 1121 & 5.2 & 11187 & 8.2 & 48239 & 15.2 & 26885 & 9.8 & 7951 & 4.6 & 2694 & 3.1 & 98077 & 9.7 \\
\hline $\begin{array}{l}\text { Top managers and employees at } \\
\text { upper level }\end{array}$ & 4843 & 22.6 & 16928 & 12.4 & 29149 & 9.2 & 27229 & 9.9 & 22738 & 13.2 & 11697 & 13.3 & 112584 & 11.1 \\
\hline Employees at intermediate level & 12052 & 56.3 & 69699 & 51.2 & 107004 & 33.7 & 89793 & 32.6 & 74701 & 43.5 & 39240 & 44.5 & 392489 & 38.8 \\
\hline $\begin{array}{l}\text { Employees at basic level or with } \\
\text { missing information on skill level }\end{array}$ & 2794 & 13.1 & 26725 & 19.6 & 104250 & 32.8 & 121719 & 44.1 & 64184 & 37.4 & 33978 & 38.6 & 353650 & 35.0 \\
\hline $\begin{array}{l}\text { Persons outside the labor market } \\
\text { or unemployed }\end{array}$ & 597 & 2.8 & 11738 & 8.6 & 28846 & 9.1 & 10220 & 3.7 & 2221 & 1.3 & 522 & 0.6 & 54144 & 5.4 \\
\hline
\end{tabular}

and men, analyses with censoring at age 70 showed similar estimates (results not shown).

Table 5 shows the excess fraction of cases and rate advancement periods among exposed men. A total of 1733 excess cases were seen, corresponding to a fraction close to $18 \%$ of all cases of THR $(\mathrm{N}=9900)$. THR was performed between 1.5-3.4 years earlier with increasing cumulative physical workload as compared to the reference group.

A decline in IEM score over three-year intervals (from 1996-2006) characterized 9\% and 12\% of the total risk time among women and men, respectively. Among both women and men, who had been employed for at least one year since 1996 in industries with an IEM score $>0$, a decline in IEM score across the preceding three-year interval predicted THR. The OR adjusted for age and calendar year were 1.5 (95\% CI 1.29-1.63) and 1.7 (95\% CI 1.61-1.89) among women and men, respectively. OR based on point-years with a time lag of three years were similar to OR based on point-years with a time lag of one year for both women (total risk time=5 340609 person-years, number of cases $=3052$ ) and men (total risk time $=5496513$ person-years, number of cases $=3915$ ).

\section{Discussion}

We evaluated the impact of cumulative physical workload to the hips (expressed in point-years) on risk of THR in the Danish working population. We showed a slight increase in risk in relation to the number of point-years, reaching a maximum OR of 1.3 for men. No 
Table 3. Risk estimates of total hip replacement due to primary osteoarthritis for women. [OR $\mathrm{R}_{\mathrm{adj}}=$ adjusted odds ratio; $95 \%$ $\mathrm{Cl}=95 \%$ confidence interval; SES=socioeconomic status]

\begin{tabular}{|c|c|c|c|c|}
\hline \multirow{2}{*}{$\begin{array}{l}\text { Exposure } \\
\text { Cumulative physical workload } \\
\text { (point-years) }^{d}\end{array}$} & \multicolumn{3}{|c|}{$O R_{a d j}{ }^{a} O R_{a d j}{ }^{b} O R_{a d j}{ }^{c}$} & \multirow[t]{2}{*}{$95 \% \mathrm{Cl}$} \\
\hline & & & & \\
\hline Reference ${ }^{\mathrm{e}}$ & 1.00 & 1.00 & 1.00 & \\
\hline & 0.97 & 0.96 & 0.96 & $0.8-1.0$ \\
\hline & 0.97 & 0.96 & 0.96 & \\
\hline & 0.94 & 0.94 & 0.94 & $0.85-1.04$ \\
\hline 25 & 0.98 & 0.98 & 0.99 & $0.88-1.10$ \\
\hline 35 & & 1.00 & 1.01 & $0.88-1.16$ \\
\hline us with 5-point-year increments & 1.00 & 1.00 & 1.00 & -1.01 \\
\hline Age, continuous with 1-year increments & & 1.11 & 1.11 & $1.11-1.11$ \\
\hline \multicolumn{5}{|l|}{ SES at age $40-55$ years } \\
\hline Self-employed and their spouses & 1.00 & & 1.00 & \\
\hline upper level) & 0.81 & & 0.85 & $0.72-0.99$ \\
\hline Emr & 0.88 & & 0.91 & $0.82-1.02$ \\
\hline $\begin{array}{l}\text { Employees (basic level or missing } \\
\text { information on skill level) }\end{array}$ & 0.82 & & 0.85 & $0.76-0.95$ \\
\hline $\begin{array}{l}\text { Persons outside the labor market or } \\
\text { unemployed }\end{array}$ & 1.09 & & 1.10 & $0.96-1.26$ \\
\hline \multicolumn{5}{|c|}{$\begin{array}{l}\text { a Adjusted for age. } \\
{ }^{\mathrm{b}} O \mathrm{R}_{\mathrm{adj}}^{\mathrm{a}}+\text { cumulative physical workload, calendar year, and county of } \\
\text { residence. } \\
{ }^{\mathrm{C}} O \mathrm{R}_{\mathrm{adj}} \mathrm{b}+\mathrm{SES} \text { and county of residence. } \\
{ }^{\mathrm{d}} \text { Years of full-time employment weighted by score of physical work- } \\
\text { load in employment industry. } \\
\text { e Never worked in industry with intermediate or high physical workload. }\end{array}$} \\
\hline
\end{tabular}

exposure-response relation was observed for women. For men, the excess fraction of cases amounted to $18 \%$ of all cases and THR occurred up to 3.4 years earlier with increasing cumulative physical workload.

We took advantage of national longitudinal registers to obtain individual information about THR, employment industry (year-by-year since 1964), duration of employment, SES, and county of residence. Using an IEM based on expert judgment, we obtained independent exposure estimates, thus avoiding recall bias, which may have inflated risk estimates in previous studies of THR (or being on a waiting list for THR) relying on self-reported exposures $(6,17,19,20,23)$. For the oldest age groups, we may have underestimated the number of point-years because the Supplementary Pension Fund Register was not created until 1964. This may have inflated the OR for lower exposure categories and thus have led to underestimation of exposure-response relations. However, analyses with censoring at age 70 showed similar estimates. We had calendar year specific information on employment industry and were able to account for transitions between industries, thereby minimizing the risk of healthy worker bias. Indeed, a decline in IEM score was related to an increased risk of THR, indicating the importance of applying cumulative exposure assessment.

Although the IEM scores corresponded well with the Canadian tripartition of professions into manual, mixed, and non-manual (33), we are aware of the weakness of the crude exposure assessment that we applied, which
Table 4. Risk estimates of total hip replacement due to primary osteoarthritis for men. [OR $\mathrm{R}_{\mathrm{adj}}=$ adjusted odds ratio; $95 \% \mathrm{Cl}=95 \%$ confidence interval; SES=socioeconomic status]

\begin{tabular}{|c|c|c|c|c|}
\hline \multirow{2}{*}{ 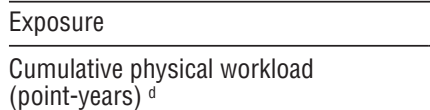 } & \multicolumn{3}{|c|}{$O R_{a d j}{ }^{a} O R_{a d j}{ }^{b} O R_{a d j}{ }^{c}$} & \multirow[t]{2}{*}{$95 \% \mathrm{Cl}$} \\
\hline & & & & \\
\hline Reference e & 1.00 & 1.00 & 1.00 & \\
\hline$>0-<5$ & 1.25 & 1.16 & 1.13 & $0.98-1.31$ \\
\hline $5-<15$ & 1.33 & 1.24 & 1.14 & $1.00-1.31$ \\
\hline $15-<25$ & 1.38 & 1.27 & 1.19 & $1.04-1.36$ \\
\hline $25-<35$ & 1.44 & 1.32 & 1.27 & $1.11-1.48$ \\
\hline $35-86$ & 1.60 & 1.39 & 1.33 & $1.17-1.53$ \\
\hline Continuous with 5-point-year increments & 1.03 & 1.02 & 1.02 & $1.02-1.03$ \\
\hline Age, continuous with 1-year increments & & 1.09 & 1.09 & $1.09-1.09$ \\
\hline \multicolumn{5}{|l|}{ SES at age $40-55$ years } \\
\hline Self-employed and their spouses & 1.00 & & 1.00 & \\
\hline Top managers/employees (upper level) & 0.58 & & 0.63 & $0.58-0.68$ \\
\hline Employees (intermediate level) & 0.72 & & 0.73 & $0.69-0.79$ \\
\hline $\begin{array}{l}\text { Employees (basic level or missing } \\
\text { information on skill level) }\end{array}$ & 0.90 & & 0.87 & $0.81-0.93$ \\
\hline $\begin{array}{l}\text { Persons outside the labor market or } \\
\text { unemployed }\end{array}$ & 0.85 & & 0.87 & $0.77-0.99$ \\
\hline
\end{tabular}

${ }^{a}$ Adjusted for age.

${ }^{b} O R_{\text {add }}{ }^{a}+$ cumulative physical workload, calendar year, and county of residence.

${ }^{c} O R_{a d j}{ }^{b}+$ SES and county of residence.

a Years of full-time employment weighted by score of physical workload in employment industry.

${ }^{\text {e }}$ Never worked in industry with intermediate or high physical workload.

may have resulted in an underestimation of true risks. For instance, some employees in industries classified as having moderate or high loads may in fact have performed administrative tasks and thus should have received minimal workload estimates. Furthermore, we did not attempt to disentangle the effects of specific physical exposures. Results from a case-control study nested within this cohort study will provide further information on risk in relation to specific exposure measures based on selfreported job titles combined with a job exposure matrix that we have developed for this purpose and accounting for individual risk factors such as obesity.

The contrasts in cumulative exposures were, to a large extent, driven by the exposure duration component, yielding a risk of residual confounding by age. Reassuringly, correlation coefficients between age and cumulative physical workload were low for both men and women. Due to the register set-up of the study, we were not able to control for body mass index and constitutional predispositions, but we do not expect these factors to be heavily skewed between industries. Among men and, to a lesser extent, also among women, we observed lower risks of THR in the lower compared to the highest SES group "self-employed and their spouses" (the reference group). The lowest risk was seen in the SES group "top managers and employees at upper level". The explanation of this finding may be that the reference group included self-employed with high physical workloads, eg, farmers and craftsmen owning small enterprises. 
Table 5. Odds ratios (OR) of total hip replacement due to primary osteoarthritis, excess fractions of cases, and rate advancement periods in a cohort of 1010944 men followed from 1 January 1996 to 31 December 2006. [ $95 \% \mathrm{Cl}=95 \%$ confidence interval; RAP=rate advancement period].

\begin{tabular}{|c|c|c|c|c|c|c|c|}
\hline & \multirow{2}{*}{$\begin{array}{c}\text { Cases } \\
\mathrm{N}\end{array}$} & \multirow[t]{2}{*}{$\mathrm{OR}_{\mathrm{adj}}{ }^{\mathrm{a}}$} & \multicolumn{2}{|c|}{ Cases (excess fraction) ${ }^{b}$} & \multirow[t]{2}{*}{ Coefficient $_{\text {adj }}{ }^{a}$} & \multirow[t]{2}{*}{ RAP (years) } & \multirow[t]{2}{*}{$95 \% \mathrm{Cl}$} \\
\hline & & & $\mathrm{N}$ & $\%$ & & & \\
\hline Age (years) & . & 1.09 & . & . & 0.0857 & . & . \\
\hline \multicolumn{8}{|c|}{ Cumulative physical workload (point-years) $\mathrm{C}$} \\
\hline Reference $^{d}$ & 242 & 1.00 & 0 & 0.0 & 0.00 & 0.0 & \\
\hline$>0-<5$ & 755 & 1.13 & 86 & 11.4 & 0.1262 & 1.5 & $-0.2-3.2$ \\
\hline $5-<15$ & 2075 & 1.14 & 254 & 12.2 & 0.1354 & 1.6 & $0.0-3.2$ \\
\hline $15-<25$ & 2447 & 1.19 & 390 & 15.9 & 0.1718 & 2.0 & $0.4-3.6$ \\
\hline $25-<35$ & 2335 & 1.27 & 496 & 21.2 & 0.2366 & 2.8 & $1.2-4.3$ \\
\hline $35-86$ & 2046 & 1.33 & 507 & 24.8 & 0.2886 & 3.4 & $1.8-4.9$ \\
\hline Total & 9900 & & 1733 & 17.5 & & . & \\
\hline
\end{tabular}

a Mutually adjusted for cumulative physical workload, age, calendar year, SES, and county of residence.

${ }^{\mathrm{b}}$ The excess fraction of cases is obtained by multiplying the aetiologic fraction, $\left(0 \mathrm{R}_{\mathrm{adj}}-1\right) / 0 \mathrm{R}_{\mathrm{adj}}$ for each exposure category with the number of cases within the exposure category, then summing up the excess numbers of cases across all exposure categories, and finally dividing the sum by the total number of cases and converting to percent.

c Years of full-time employment weighted by score of physical workload in employment industry.

${ }^{d}$ Never worked in an industry with intermediate or high physical workload.

In accordance with recent recommendations, we performed analyses stratified by sex (37). The exposure distribution for women was skewed towards lower cumulative physical workload than for men. Thus, effects of high exposures were less well explored among women, meaning that we may have overlooked effects of high exposures. Furthermore, our results probably underestimated risks especially among women because women in industries with high exposures would be more likely to hold jobs with minimal physical workload, eg, office jobs. A greater tendency towards exposure misclassification for women than men may be part of the explanation why we only found an exposure-response relation for men. Maybe more valid exposure estimates could have been obtained if our IEM had been made for women and men separately. However, the Danish labor market is, to a large extent, gender segregated, so the practical significance of such an effort may be limited.

Health service is free of charge in Denmark. Valid information on THR can be obtained from the NPR, where, in general, there is a very good agreement between medical records and registered information on surgical interventions (38). We had no information on hospital diagnoses of hip OA prior to the establishment of the NPR in 1977, but THR was uncommon until the late 1970s. Thus, we do not suspect any significant misclassification of the outcome.

To our knowledge, the present study is the first longitudinal study examining the risk and timing of THR due to OA at the population level in relation to independently assessed lifelong cumulative physical workload. Our findings were in accordance with earlier findings of an increased risk of THR among men in relation to duration of employment in selected physically demanding jobs $(18,19,21)$. Andersen et al (21) classified the vast majority of the Danish work force into five occupational groups. In our study, these jobs would be assigned an IEM score of 2 (construction workers, floorand bricklayers, farmers), an IEM score of 1 (healthcare assistants), or an IEM score of 0 (office workers). The excess fraction of all cases in the study by Andersen et al (21) amounted to $27.5 \%$ (2301 out of 8353 cases) among men and 5.5\% (443 out of 8056 cases) among women (our calculations). For women, employment in industries covered by our IEM group 2 contributed with only $8 \%$ of the total risk time (21). In the study by Andersen et al (21) the reference group of office workers may have differed from the group of healthcare assistants, where the majority of the exposed females were employed, with respect to possible confounders such as a high body mass index, and this may have inflated the risk estimates. We have identified one other study regarding the risk of THR among women in relation to cumulative physical workload (20); the study was based on self-reported generic exposures that were collected retrospectively, and therefore, it is likely that recall bias may have contributed to the positive association, which was observed. Thus, the two positive studies may have overestimated risks, whereas our negative study may have underestimated them especially among women. We plan to look deeper into the impact of cumulative physical workload on risk of THR among men and women in the aforementioned case-control study nested within the present cohort study.

The present study comprised the Danish working population with at least ten years of full-time employment. We think that the results can be generalized to working populations in countries with similar working conditions and easy access to THR.

In spite of the fact that all identified sources of bias in the present study would lead to underestimated risks, we did find an exposure-response relation between 
lifelong cumulative physical workload to the hips and risk of primary hip OA leading to THR among men. The excess fraction of cases among men was $18 \%$, and THR was performed up to 3.4 years earlier with increasing exposure, which we find impressive considering the fact that we most likely underestimated associations. Among women, we found no exposure-response relation, which may well be explained by lower exposure levels and a larger degree of exposure misclassification. The proportion of the working population that was employed in the most highly exposed industries stayed constant over a 20 -year period. Thus, from a public health perspective, our results suggested that, at least among men, there is an unutilized potential for prevention.

\section{Acknowledgments}

The study was supported by a grant from the Danish Ministry of Health and Prevention (grant number: 20071022-62). We thank Michael Væth, Professor, Department of Biostatistics, School of Public Health, Aarhus University, Denmark, for his statistical guidance.

\section{References}

1. Arden N, Nevitt MC. Osteoarthritis: epidemiology. Best Pract Res Clin Rheumatol. 2006;20(1):3-25. http://dx.doi. org/10.1016/j.berh.2005.09.007.

2. Overgaard S. Dansk Hoftealloplastik Register. Årsrapport 2011 [Danish Hip Arthroplasty Register. Annual report 2011] [Internet]. Odense: Dansk Hoftealloplastik Register [Danish Hip Arthroplasty Register]; [cited 11 December 2012]. Available from: http://www.dhr.dk/Ny\%20mappe/rapporter/ DHR\%20Aarsrapport_2011\%20t_web.pdf.

3. Birrell F, Afzal C, Nahit E, Lunt M, Macfarlane GJ, Cooper $\mathrm{C}$, et al. Predictors of hip joint replacement in new attenders in primary care with hip pain. Br J Gen Pract. 2003;53(486):26-30.

4. Petersson IF, Jacobsson LT. Osteoarthritis of the peripheral joints. Best Pract Res Clin Rheumatol. 2002;16(5):741-60. http://dx.doi.org/10.1053/berh.2002.0266

5. Felson DT, Lawrence RC, Dieppe PA, Hirsch R, Helmick CG, Jordan JM, et al. Osteoarthritis: new insights. Part 1: the disease and its risk factors. Ann Intern Med. 2000;133(8):635-46.

6. Lau EC, Cooper C, Lam D, Chan VN, Tsang KK, Sham A. Factors associated with osteoarthritis of the hip and knee in Hong Kong Chinese: obesity, joint injury, and occupational activities. Am J Epidemiol. 2000;152(9):855-62. http://dx.doi. org/10.1093/aje/152.9.855.

7. Lievense AM, Bierma-Zeinstra SM, Verhagen AP, van Baar ME, Verhaar JA, Koes BW. Influence of obesity on the development of osteoarthritis of the hip: a systematic review. Rheumatology (Oxford). 2002;41(10):1155-62. http://dx.doi. org/10.1093/rheumatology/41.10.1155.

8. Aigner T, Rose J, Martin J, Buckwalter J. Aging theories of primary osteoarthritis: from epidemiology to molecular biology. Rejuvenation Res. 2004;7(2):134-45. http://dx.doi. org/10.1089/1549168041552964.

9. Jensen LK. Hip osteoarthritis: influence of work with heavy lifting, climbing stairs or ladders, or combining kneeling/ squatting with heavy lifting. Occup Environ Med. 2008;65(1):6 19. http://dx.doi.org/10.1136/oem.2006.032409.

10. Lievense A, Bierma-Zeinstra S, Verhagen A, Verhaar J, Koes B. Influence of work on the development of osteoarthritis of the hip: a systematic review. J Rheumatol. 2001;28(11):2520-8.

11. Schouten JS, de Bie RA, Swaen G. An update on the relationship between occupational factors and osteoarthritis of the hip and knee. Curr Opin Rheumatol. 2002;14(2):89-92. http://dx.doi.org/10.1097/00002281-200203000-00002.

12. Sulsky SI, Carlton L, Bochmann F, Ellegast R, Glitsch U, Hartmann B, et al. Epidemiological evidence for work load as a risk factor for osteoarthritis of the hip: a systematic review. PLoS One. 2012;7(2):e31521. http://dx.doi.org/10.1371/ journal.pone.0031521.

13. Vignon E, Valat JP, Rossignol M, Avouac B, Rozenberg $\mathrm{S}$, Thoumie P, et al. Osteoarthritis of the knee and hip and activity: a systematic international review and synthesis (OASIS). Joint Bone Spine. 2006;73(4):442-55. http://dx.doi. org/10.1016/j.jbspin.2006.03.001.

14. Croft P, Coggon D, Cruddas M, Cooper C. Osteoarthritis of the hip: an occupational disease in farmers. BMJ. 1992;304(6837):1269-72. http://dx.doi.org/10.1136/ bmj.304.6837.1269.

15. Croft P, Cooper C, Wickham C, Coggon D. Osteoarthritis of the hip and occupational activity. Scand J Work Environ Health. 1992;18(1):59-63. http://dx.doi.org/10.5271/ sjweh.1608.

16. Roach KE, Persky V, Miles T, Budiman-Mak E. Biomechanical aspects of occupation and osteoarthritis of the hip: a casecontrol study. J Rheumatol. 1994;21(12):2334-40.

17. Coggon D, Kellingray S, Inskip H, Croft P, Campbell L, Cooper C. Osteoarthritis of the hip and occupational lifting. Am J Epidemiol. 1998;147(6):523-8. http://dx.doi. org/10.1093/oxfordjournals.aje.a009483.

18. Thelin A. Hip joint arthrosis: an occupational disorder among farmers. Am J Ind Med. 1990;18(3):339-43. http://dx.doi. org/10.1002/ajim.4700180316.

19. Vingard E, Hogstedt C, Alfredsson L, Fellenius E, Goldie I, Koster M. Coxarthrosis and physical work load. Scand J Work Environ Health. 1991;17(2):104-9. http://dx.doi.org/10.5271/ sjweh.1727.

20. Vingård E, Alfredsson L, Malchau H. Osteoarthrosis of the hip in women and its relation to physical load at work and in the home. Ann Rheum Dis. 1997;56(5):293-8. http://dx.doi. org/10.1136/ard.56.5.293.

21. Andersen S, Thygesen LC, Davidsen M, Helweg-Larsen K. Cumulative years in occupation and the risk of hip or knee osteoarthritis in men and women: a register-based follow-up study. Occup Environ Med. 2012;69(5):325-30. http://dx.doi. 
org/10.1136/oemed-2011-100033.

22 Franklin J, Ingvarsson $\mathrm{T}$, Englund M, Lohmander S. Association between occupation and knee and hip replacement due to osteoarthritis: a case-control study. Arthritis Res Ther. 2010;12(3):R102. http://dx.doi.org/10.1186/ar3033.

23 Yoshimura N, Sasaki S, Iwasaki K, Danjoh S, Kinoshita H, Yasuda T, et al. Occupational lifting is associated with hip osteoarthritis: a Japanese case-control study. J Rheumatol. 2000;27(2):434-40.

24. Flugsrud GB, Nordsletten L, Espehaug B, Havelin LI, Meyer HE. Risk factors for total hip replacement due to primary osteoarthritis: a cohort study in 50,034 persons. Arthritis Rheum. 2002;46(3):675-82. http://dx.doi.org/10.1002/art.10115.

25. Järvholm B, From C, Lewold S, Malchau H, Vingård E. Incidence of surgically treated osteoarthritis in the hip and knee in male construction workers. Occup Environ Med. 2008;65(4):275-8. http://dx.doi.org/10.1136/ oem.2007.033365.

26. Brenner H, Gefeller O, Greenland S. Risk and rate advancement periods as measures of exposure impact on the occurrence of chronic diseases. Epidemiology. 1993;4(3):229 36. http://dx.doi.org/10.1097/00001648-199305000-00006.

27. Seidler A, Euler U, Bolm-Audorff U, Ellegast R, Grifka J, Haerting J, et al. Physical workload and accelerated occurrence of lumbar spine diseases: risk and rate advancement periods in a German multicenter case-control study. Scand J Work Environ Health. 2011;37(1):30-6. http://dx.doi.org/10.5271/ sjweh.3121.

28. Greenland S. Relation of probability of causation to relative risk and doubling dose: a methodologic error that has become a social problem. Am J Public Health. 1999;89(8):1166-9. http://dx.doi.org/10.2105/AJPH.89.8.1166.

29. Pedersen CB. The Danish Civil Registration System. Scand J Public Health. 2011;39(7 Suppl):22-5. http://dx.doi. org/10.1177/1403494810387965.

30. Hansen J, Lassen CF. The Supplementary Pension Fund Register. Scand J Public Health. 2011;39(7 Suppl):99-102. http://dx.doi.org/10.1177/1403494810394716.
31. Lynge E, Sandegaard JL, Rebolj M. The Danish National Patient Register. Scand J Public Health. 2011;39(7 Suppl):30-3. http://dx.doi.org/10.1177/1403494811401482.

32. Volder L, Torma K, Sørensen C, Thisgaard C, Wessing MH. Dansk branchekode 2003 [Danish Industrial Classification of All Economic Activities 2003] [Internet]. København: Danmarks Statistik [Statistics Denmark]; cited 11 December 2012. Available from: http://www.dst.dk/pukora/epub/ upload/5132/hele1.pdf.

33. Hébert F, Duguay P, Massicolte P, Lévy M. Révision des categories professionelles utilisées dans les etudes de l'IRSST portant sur les indicateurs quinquennaux de lésions profesionnelles [Review of occupational categories used in IRSST studies on the five-year indicators of occupational injuries] [Internet]. Montreal: IRSST; 1996; [cited December 11 2012]. Available from: https://www.irsst.qc.ca/media/ documents/PubIRSST/R-137.pdf.

34. Friesen MC, Davies HW, Ostry A, Teschke K, Demers PA. Impact of expert versus measurement-based occupational noise exposure estimates on exposure-response relationships. Int Arch Occup Environ Health. 2008;81(7):837-44. http:// dx.doi.org/10.1007/s00420-007-0274-0.

35. Richardson DB. Discrete time hazards models for occupational and environmental cohort analyses. Occup Environ Med. 2010;67(1):67-71. http://dx.doi.org/10.1136/ oem.2008.044834.

36. Greenland S, Robins JM. Conceptual problems in the definition and interpretation of attributable fractions. Am J Epidemiol. 1988;128(6):1185-97.

37. Messing K, Silverstein BA. Gender and occupational health. Scand J Work Environ Health. 2009;35(2):81-3. http://dx.doi. org/10.5271/sjweh.1314.

38. Andersen TF, Madsen M, Jørgensen J, Mellemkjær L, Olsen JH. The Danish National Hospital Register. A valuable source of data for modern health sciences. Dan Med Bull. 1999;46(3):263-8.

Received for publication: 31 December 2012 